\title{
Comparative tribological behavior of friction composites containing natural graphite and expanded graphite
}

\author{
Hongyun JIN ${ }^{1}$, Keke ZHOU ${ }^{1}$, Zhengjia $\mathrm{JI}^{1}$, Xiaocong TIAN ${ }^{1}$, Ying CHEN ${ }^{1}$, Luhua $\mathrm{LU}^{1}$, Yazhou REN ${ }^{1}$, Chunhui XU ${ }^{1}$, \\ Shanshan DUAN ${ }^{1}$, Jiangyu LI ${ }^{1,2}$, Shu-en HOU ${ }^{1, *}$ \\ ${ }^{1}$ Faculty of Materials Science and Chemistry, China University of Geosciences, Wuhan 430074, China \\ ${ }^{2}$ Department of Mechanical Engineering, University of Washington, Seattle, WA 98195-2600, USA \\ Received: 10 Nov 2018 / Revised: 03 Feb 2019 / Accepted: 31 Mar 2019 \\ (C) The author(s) 2019.
}

\begin{abstract}
In this study, expanded graphite and natural graphite were introduced into resin-based friction materials, and the tribological behavior of the composites was investigated. The tribo-performance of the two friction composites was evaluated using a constant speed friction tester. The results showed that the expanded graphite composite (EGC) displayed better lubricity in both the fading and the recovery processes. The wear rate of the EGC decreased by $22.43 \%$ more than that of the natural graphite composite (NGC). In the fading process, and the EGC enhanced the stability of the coefficient of friction. The recovery maintenance rate of the NGC was $4.66 \%$ higher than that of the EGC. It can be concluded that expanded graphite plays an important role in the formation of a stable contact plateau and can effectively reduce the wear.
\end{abstract}

Keywords: natural graphite; expanded graphite; tribological behavior; wear mechanism

\section{Introduction}

Non-asbestos organic (NAO) friction materials, such as multi-ingredient polymer matrix composites with complex formulations, are used extensively in the transportation and mechanical industries. The formulation of friction materials is one of the most complex tasks in the area of materials science. Four main categories of raw materials exist for creating resin-based friction materials, specifically binders, intensifiers, friction modifiers, and fillers. The friction modifier category includes both abrasives and solid lubricants [1, 2].

Solid lubricants play an important role in reducing the wear rate $[3,4]$ and in facilitating smooth-sliding and a stable coefficient of friction under a wide range of pressures, speeds, and environmental conditions [5]. Due to their high thermal conductivity, layered structure, capacity for dispersing friction-generated heat, and relatively stable coefficients of friction, natural graphite (NG) and synthetic graphite are often used as solid lubricants in friction materials [6-8]. Kolluri et al. [9] demonstrated the particle size effect of NG in friction composites on the thermal localization phenomenon in braking. They found that the composites containing smaller graphite particles achieved better results than those with larger particles. Baptista et al. [10] investigated the effect of high content graphite on the tribological and mechanical behavior of epoxy-based composites, suggesting that an increase in graphite filler could reduce the fatigue-related wear experienced by epoxy resin. Other types of graphite have also been studied, but are not the focus of this particular paper [11].

Despite the research undertaken to date, achieving desired performance levels using NG still poses a major challenge due to its low dispersion and thermal conductivity in composite materials. Some studies have approached the problem by experimenting with varieties of specially treated graphite with higher thermal

* Corresponding author: Shu-en HOU, E-mail: 13476118841@126.com 
conductivity. Panda et al. [12] proposed a heat-treated graphite, which achieved better lubrication within a certain pressure range. Aranganathan and Bijwe [7, 13] investigated the tribological behavior of graphite composites with high thermal conductivity and found these showed a lower rate of wear. These results indicate that thermo-graphite offers improved lubricity and wear resistance to friction.

Expanded graphite (EG) is also a specially treated graphite, produced by further expansion of NG after high-temperature expansion. EG offers a high surface area $\left(100-380 \mathrm{~m}^{2} / \mathrm{g}\right)$, abundant structural defects, residual oxygen-containing groups, sufficient reinforcing capacity, valuable barrier properties, and good heat conductance [14]. Due to EG's unique structure it can be combined with other materials to improve both their thermal and adsorption properties [15, 16]. Dinker et al. [17] investigated the efficacy of a beeswax/EG composite as a thermal storage material, finding that the combination of high thermal stability and lubrication effect made this material a promising candidate for new tribological materials for enhanced wear resistance. They showed that the wear rate of a polytetrafluoroethylene (PTFE)/EG composite can be reduced by up to $50 \%$ more than that of a commercial grade PTFE/graphite composite [18]. Wang et al. [19] found that nitrile-butadiene rubber/EG nanocomposites exhibited better wear resistance than micro-composites, and Jia et al. [20] showed the effects of nanoscale EG on the frictional and wear behaviors of polyimide (PI)-based friction material. The best tribological properties and the lowest wear rate were obtained at a nanoscale EG content of $15 \%$. The effect of ultrasound treatment of EG ( $5 \mathrm{wt} \%)$ on the tribological behavior of PTFE/EG composites was also studied, with results indicating that the wear rate of composites could be reduced more than twenty-fold by increasing the tribochemical wear resistance mechanism [14]. From these studies it can be concluded that EG exhibits good lubricity and wear resistance, and thus has potential for use in a NAO friction system.

On the basis of the findings outlined above, EG and NG are introduced into the NAO friction materials system in this work to produce expanded graphite composite (EGC) and natural graphite composite (NGC), respectively, and the friction performance of each composite is systematically tested and measured. In order to discuss the effect of solid lubricants on the friction properties more accurately, the composition of the composites is simplified. Although there is no abrasive in the friction material formula, it does allow for the testing of certain tribological behavior relevant to the use of solid lubricant.

\section{Materials and methods}

EG and NG were procured from Qingdao Pingdu Xinsheng Graphite Co., Ltd., China. Both kinds of graphite were analytical reagents with a carbon content greater than $99 \%$ and a mesh number of 100 .

\subsection{Characterization of graphite}

Figures 1 and 2 show the X-ray diffraction (XRD) patterns and scanning electron microscopy (SEM) micrographs for the obtained NG and EG, respectively.

As shown in Fig. 1, six clear diffraction peaks are observed at $26.43^{\circ}, 42.05^{\circ}, 43.60^{\circ}, 49.02^{\circ}, 50.96^{\circ}$, and $54.58^{\circ}$ for EG. These diffraction peaks can be indexed to corresponding lattice planes at positions (002), (100), (101), (300), (102), and (004) of the hexagonal graphite (JCPDS Card No. 25-0284). In contrast, there are only two main diffraction peaks for NG, which can be observed at $26.70^{\circ}$ and $54.70^{\circ}$. Compared to NG, the diffraction peak of lattice plane (002) for EG is broader and of lower intensity, $0.27^{\circ}$ lower than that of NG, with a lattice constant that is $0.034 \AA$ higher. This indicates that expanded graphite has larger interlayer spacing. In fact, the diffraction peak at the (002) crystal surface may shift a degree further to the left because

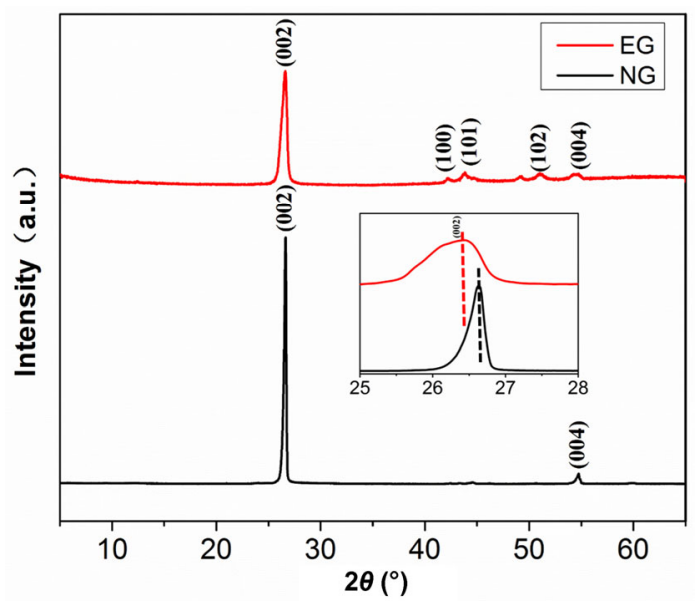

Fig. 1 XRD patterns of NG and EG. 

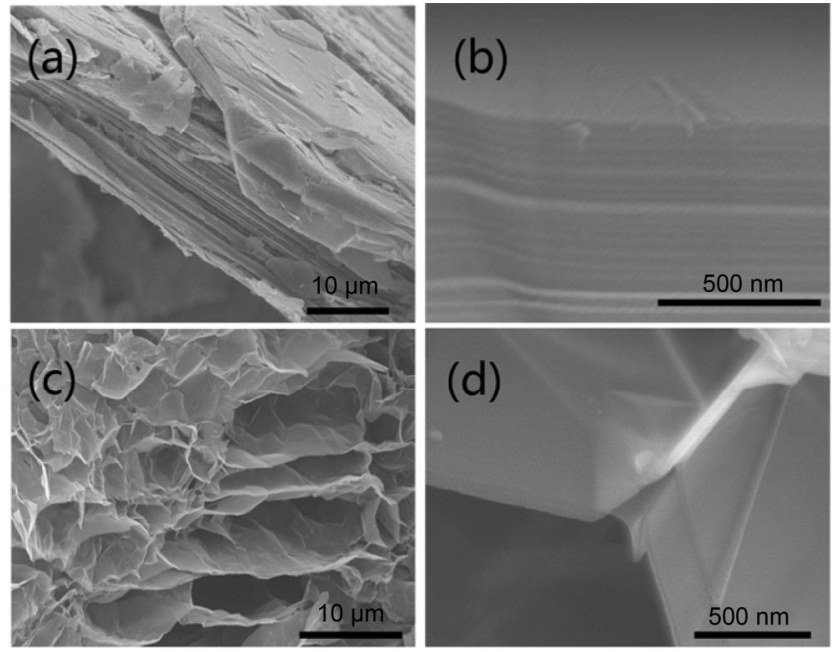

Fig. 2 SEM micrographs of $(a-b) N G$ and $(c-d)$ EG.

the surface of the sample must be flattened before the test, impacting the results.

As shown in Fig. 2, the morphology of the two types of graphite differs significantly. Figure 2 shows the NG comprises of closely arranged flakes, whereas the EG can be seen to be porous with a much larger interlayer spacing than that of the NG. The EG layer spacing ranged from 5 to $10 \mu \mathrm{m}$, whereas the lamella thickness of the graphite was almost identical, $\sim 50 \mathrm{~nm}$. The spacing of the graphite cells in the (002) crystal plane was $\sim 0.33 \mathrm{~nm}$. Therefore, even if the EG's small interlayer spacing was to increase, the offset of the XRD pattern of the two types of graphite would not increase. This is consistent with the results as shown in Fig. 1.

\subsection{Formulation and designation of the friction composites}

Friction composites were designed (denoted NGC and EGC, respectively) with equal parent composition, but differing in terms of solid lubricant composition, as listed in Table 1. Straight phenolic resin was provided by Jinan Shengquan Co., Ltd., China (model: PF8616). Aramid pulp with an average diameter of $3 \mu \mathrm{m}$ was obtained from Changzhou Bangguan Chemical Co., Ltd., China.

Table 1 Ingredients and mass fraction (wt\%) of the friction composites.

\begin{tabular}{cccccc}
\hline & Phenolic resin & Aramid pulp & Barite & NG & EG \\
\hline NGC & 15 & 20 & 60 & 5 & 0 \\
EGC & 15 & 20 & 60 & 0 & 5 \\
\hline
\end{tabular}

\subsection{Preparation of friction specimens}

Aramid pulp was first mixed to prevent it from agglomerating, and then other ingredients were added. All the ingredients were mixed four times using a high-speed mixer. Then, friction specimens were prepared by hot-press molding under a pressure of $80 \mathrm{MPa}$ at $160{ }^{\circ} \mathrm{C}$ for $6 \mathrm{~min}$. Three interrupted respirations of $4 \mathrm{~s}$ duration were followed by a hot pressing period to expel volatiles including the gas produced by the phenolic resin's crosslinking process. The pressed friction specimens, $\sim 25 \mathrm{~mm} \times 25 \mathrm{~mm} \times$ $6 \mathrm{~mm}$ in size, were removed from the mold and maintained at $180^{\circ} \mathrm{C}$ for $4 \mathrm{~h}$ in a hot oven to release internal residual stress. Finally, they were polished with an abrasive paper to ensure larger contact areas for friction performance measurement. The final density was $2.13 \mathrm{~g} / \mathrm{cm}^{3}$ for both composites.

\subsection{Tribological testing set up and test procedure}

The friction behavior of NGC and EGC was evaluated using a constant speed friction tester (model: XD-MSM, Xianyang Xinyi friction sealing equipment Co., Ltd.) according to Chinese national standard GB 5763-2008. As shown in Fig. 3, the disc was positioned at the bottom and the specimens were fixed above the disc. In order to obtain more reliable test data, specimens of two identical components were placed in the corresponding slot above the disc.

During the test, the disk rotated continuously at $7.85 \mathrm{~m} / \mathrm{s}$. The pressure on the specimen was kept at $0.98 \mathrm{MPa}$. The disc was HT-250 gray iron (HB: 180-220;

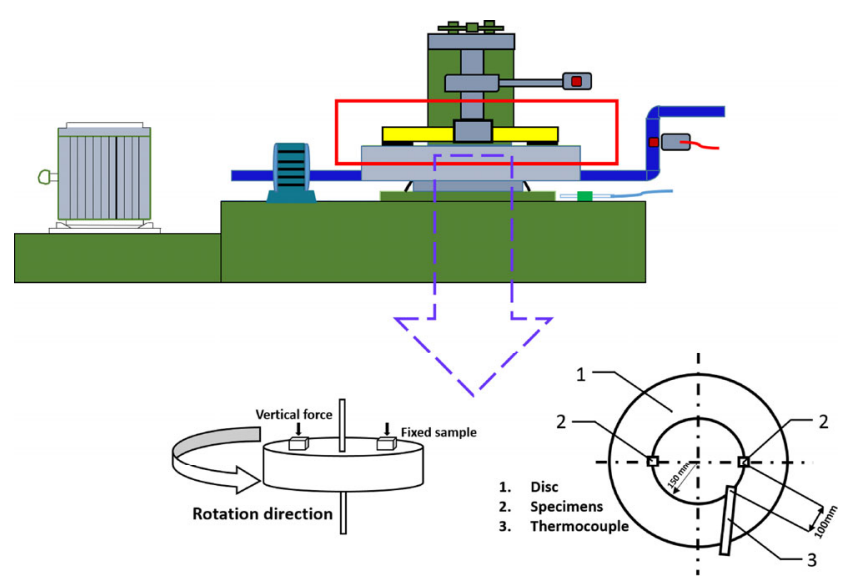

Fig. 3 Schematic of the friction tester showing the installation position of the specimens. 
$\left.R_{\mathrm{a}}=0.1-0.2\right)$ with a radius of $15 \mathrm{~cm}$, capable of producing a moment of inertia of $0.26 \mathrm{~kg} \cdot \mathrm{m}^{2}$. All the specimens were ground at $100{ }^{\circ} \mathrm{C}$ before the formal test to ensure a contact area greater than $95 \%$.

The friction performance test is divided into two sections, namely the fade and recovery processes, corresponding to the heating and cooling processes, respectively. The temperature was raised in $50{ }^{\circ} \mathrm{C}$ increments from 100 to $300{ }^{\circ} \mathrm{C}$, with the temperature remaining constant for $10 \mathrm{~min}$ at each incremental step. At each aforementioned increment, the computer was connected to the tester and automatically recorded the coefficient of friction and mass of each specimen for that particular temperature. The heat needed to increase the temperature came from 2 sources, heating pipes and the friction generated by the experiment. Cooling was dependent on the circulation of water under the disc, controlled by solenoid valves. The temperature was measured using a thermocouple.

The wear experienced by the specimens was determined using the weight of each as recorded before and after each temperature test. The wear rate was calculated using the following equations:

$$
\begin{aligned}
& \text { Wear rate }(\mathrm{wt} \%)=\frac{m_{1}-m_{2}}{m_{1}} \times 100 \% \\
& \text { Total wear rate }(\mathrm{wt} \%)=\frac{m_{3}-m_{4}}{m_{3}} \times 100 \%
\end{aligned}
$$

where $m_{1}$ and $m_{2}$ are the weight before and after the test at each specific temperature, respectively, and $m_{3}$ and $m_{4}$ are the weight before and after the full testing period, respectively.

According to Ref. [21], the fade ratio and recovery ratio are defined as follows:

$$
\begin{aligned}
R_{\text {fade }} & =\frac{\mu_{\mathrm{f}-3500^{\circ} \mathrm{C}}}{\mu_{\mathrm{f}-\max }} \times 100 \% \\
R_{\text {recovery }} & =\frac{\mu_{\mathrm{r}-100^{\circ} \mathrm{C}}}{\mu_{\mathrm{r}-\max }} \times 100 \%
\end{aligned}
$$

where $\mu$ is the coefficient of friction, $\mu_{\mathrm{f}}$ is the coefficient of friction of the fade process (heating process), and $\mu_{\mathrm{r}}$ is the coefficient of friction of the recovery process (cooling process).

The coefficient of variation (CV) is a measure of relative dispersion. It describes the standard deviation as a percentage of the arithmetic average. $\mathrm{CV}$ can be used to measure the relative degree of dispersion of the coefficient of friction. As such, the stability of the coefficient of friction in the fade and recovery processes was measured using CV. The lower the value of $\mathrm{CV}$, the better the stability of the coefficient of friction, as follows:

$$
\mathrm{CV}=\frac{\sigma_{\mu}}{\bar{\mu}} \times 100 \%
$$

where $\bar{\mu}$ is the average coefficient of friction, and $\sigma_{\mu}$ is the standard deviation of the coefficient of friction.

XRD patterns were collected using an X'Pert Pro X diffractometer equipped with $\mathrm{Cu} \mathrm{K} \alpha$ radiation $(\lambda=$ $0.15416 \mathrm{~nm}$ ). Following the tribological performance testing, the microstructure of the two types of graphite, their wear surfaces, and the corresponding crosssectional views of their friction composites were observed using an HR-FESEM (model: SU8010, Hitachi company) in order to determine their friction and wear mechanisms.

A synchronous heat analyzer (model: STA 449F3, NETZSCH company) was used to characterize the weight loss of the specimens before and after the friction test. The specimens were dried in an oven at $80^{\circ} \mathrm{C}$ for $1 \mathrm{~h}$ before the heat analysis test. The test temperature range was from room temperature to $800{ }^{\circ} \mathrm{C}$. The test was carried out in a simulated air atmosphere consisting of nitrogen and oxygen, at a heating rate of $3{ }^{\circ} \mathrm{C} / \mathrm{min}$. The weight of all specimens was approximately $8 \mathrm{mg}$. During the test, the nitrogen and oxygen flow rates were maintained at 50 and $20 \mathrm{ml} / \mathrm{min}$, respectively. The specimen was well dispersed.

In the process of testing, each formula was set up with three groups in parallel, and the average values of the three groups were analyzed.

\section{Results and discussion}

\subsection{Tribological performance}

In this section, the coefficient of friction and the wear rate during the fade and recovery processes are explained, with the results shown in Figs. 4 and 5 . Moreover, several different methods are used to describe the stability of the coefficient of friction, as shown in Fig. 6. 

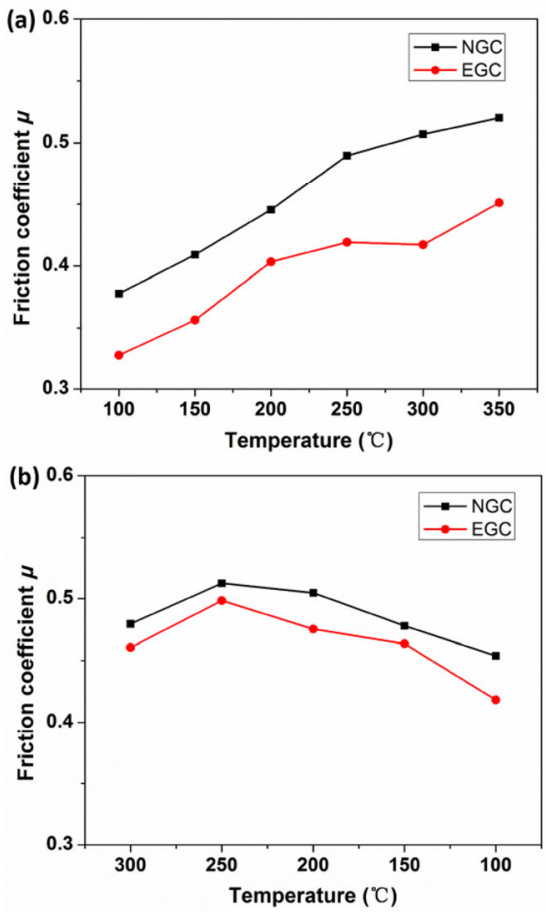

Fig. 4 Coefficients of friction for: (a) fade process and (b) recovery process.

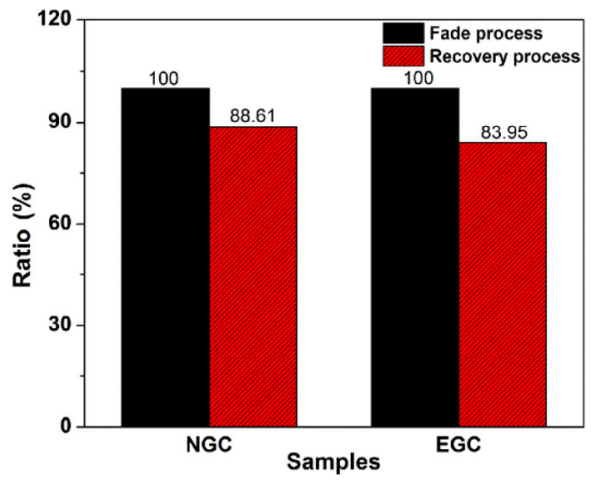

Fig. 5 Fade ratio and recovery ratio of the friction materials.

\subsubsection{Fade and recovery test}

Figure 4 shows the coefficient of friction of the friction composites with respect to the temperature.

The coefficient of friction of the specimens increased with increasing temperature during the fade testing process (Fig. 4(a)). As shown in Fig. 4(b), the coefficient of friction of the specimens increased when the temperature decreased from 300 to $250{ }^{\circ} \mathrm{C}$ during the recovery process, but conversely, decreased when the temperature decreased in the subsequent process. The reason for the increase in the coefficient of friction during the fade process is that the resin undergoes glass transition, causing the matrix of the friction

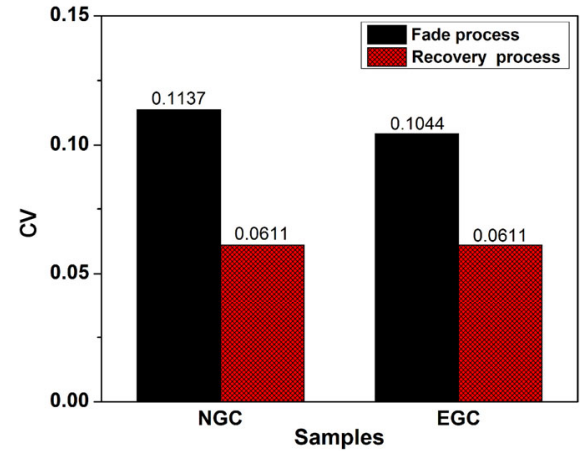

Fig. 6 Stability of the coefficient of friction: CV.

material to become softer and easier to scratch [22]. In the recovery process, especially at temperatures above $250{ }^{\circ} \mathrm{C}$, the surface of the disc was easily scratched by hard particles.

The increased coefficient of friction resulted from scratching caused by the pairing disc at high temperatures. With decreasing the temperature, the scratched debris fell onto the surface of the disc, creating a compacted area in a process termed falling compaction. This compacted area is often called the secondary plateau, and can easily accumulate to form a thicker friction layer which can reduce the coefficient of friction and prevent further particle loss. Figure 4 clearly shows that EGC maintained a lower coefficient of friction than NGC throughout the testing process, probably due to the enhanced EG's self-lubrication. Although the coefficient of friction was reduced to a certain extent, it could still be maintained within the $0.3-0.5$ range while ensuring the braking effect.

\subsubsection{Fade ratio and recovery ratio}

The fade ratio was found to be $100 \%$ for both NGC and EGC (Fig. 5). The study found that the coefficient of friction of the two composites reached its maximum at $350^{\circ} \mathrm{C}$. However, the order of the recovery ratio indicated that NGC > EGC. The recovery rate of NGC was $4.66 \%$ higher than that of EGC, probably because the chemical bonds were destroyed by the graphite intercalation on compounds in EG. It is therefore suggested that recovery maintenance would be dropped for porous and damaged graphite. The results showed that NGC also had a better recovery maintenance rate.

\subsubsection{Stability of the coefficient of friction}

The coefficient of variation, $\mathrm{CV}$, is a key indicator used 
to demonstrate stability in braking [23-25]. The lower the value of $\mathrm{CV}$, the more stable the coefficient of friction.

Figure 6 shows that the $\mathrm{CV}$ of the fade process is significantly larger than that of the recovery process. Therefore, the recovery process possesses better friction stability for every specimen than the fade process does. This may be due to the fact that the full recovery process is shorter than the fade process, resulting in less time for the coefficient of friction to change.

The stability of NGC is the same as that of EGC in the recovery process. However, the stability of EGC is better in the fade process $(0.1044<0.1137)$. The experimental results may be attributed to the fact that EG is not easily removed from the composite during the test, moreover, causes the formation of a thicker friction layer, thus ensuring the stability of the friction performance.

\subsection{Wear performance}

The weight-loss measurements were made for every specimen at each specific temperature after 5,000 revolutions. Figure $7(\mathrm{a})$ shows that the wear rate of EGC is lower than that of NGC, especially for the high-temperature period. The wear resistance of the friction materials was improved remarkably by the presence of porous EG. This may be attributed to the fact that other powders become coated with porous EG. Figure 7(b) shows the total wear rate over the full testing period. It can be seen that the total wear rate of EGC is lower, consistent with the results shown in Fig. 7(a). The total wear rate decreased from $3.70 \%$ to $2.87 \%$.

\subsection{Worn surfaces analysis}

The wear rate of EGC decreased by $22.43 \%$ compared to that of NGC. The results showed that the EG's larger interlayer spacing and porous microstructure enable EG to coat other composite powders, and thereby to improve the wear resistance of EGC. It can be concluded that porous EG can be used as a solid lubricant to improve the wear resistance of composites.

In order to further understand the effect on the wear mechanism of graphite varieties with different microstructures, the worn surfaces and corresponding cross-sectional views of the friction layers of composites were examined. Figure 8 shows the SEM micrographs
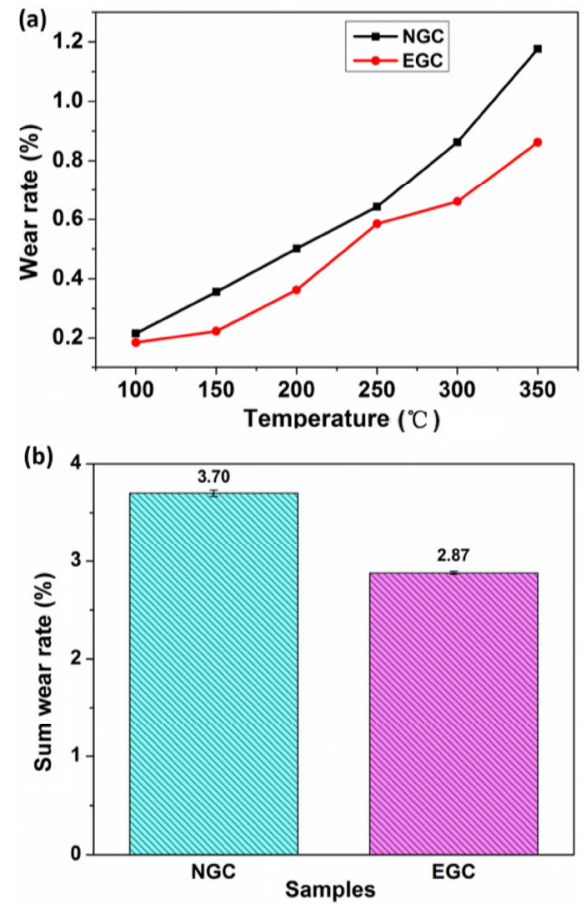

Fig. 7 Effect of graphites with different microstructures on the wear rate of the friction materials: (a) wear rates at different temperatures and (b) the total wear rate.
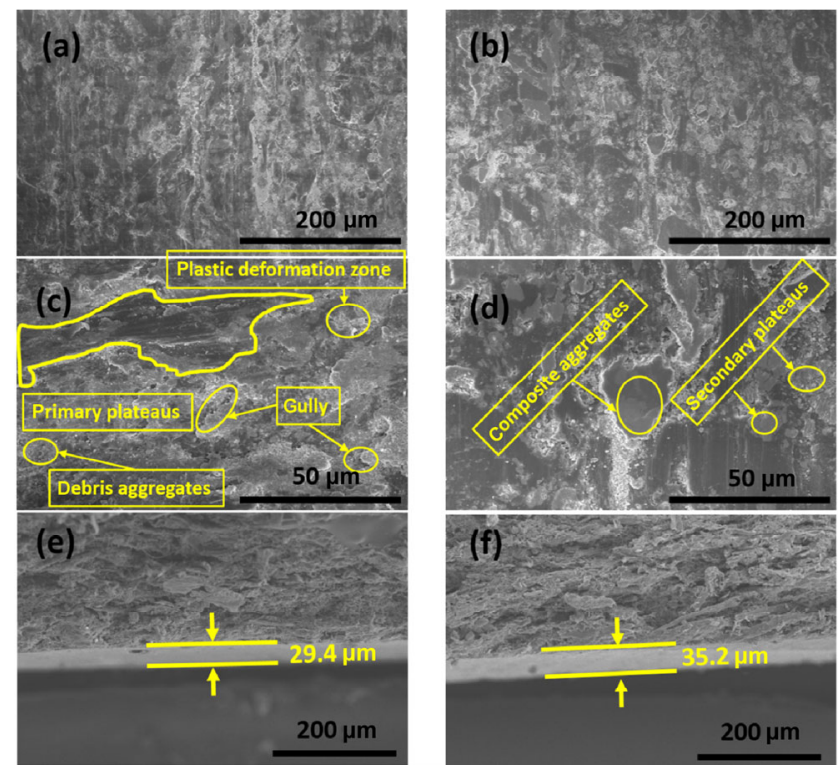

Fig. 8 SEM micrographs of worn surfaces and cross sections of the friction materials after testing: (a, c, e) NGC and (b, d, f) EGC ((a, b): $250 \times,(c, d): 1000 \times$, and (e, f) cross sections: $200 \times)$.

of the worn-out surfaces of the NGC and the EGC specimens. From Figs. 8(a) and 8(c), it can be seen that the worn surface of NGC was severely damaged. It has a rough gully with primary plateaus and debris aggregates. In Fig. 8(c), we can also see the plastic 
deformation area. With the increase in temperature, the frictional contact surface gradually changed from an elastic state to a plastic state, resulting in more debris. The primary plateaus were derived from the removal of the least hardy component of the friction composites, the aramid pulp, being worn out and leaving barite protruding from the surface. This caused the surface to be scratched, rapidly further increasing both the wear and the wear rate.

Figures 8(b) and 8(d) show that, after the fractioning test, the surface of EGC is smooth, whereas NGC has clear scratches. As shown in the worn surfaces and relevant cross-sectional diagrams of the specimens (Figs. 8(d) and 8(f)), the friction layers mainly composed of component-dense composite aggregates and relatively compact secondary plateaus. Although the composite particles of EGC were exposed, the existence of dense composite aggregates and secondary plateaus prevented further particle loss.

Figures 8(e) and 8(f) show the difference in the thickness of the friction layer between the NGC $(35.2 \mu \mathrm{m})$ and the EGC $(29.4 \mu \mathrm{m})$. The EG is believed to aid in the formation of a thick friction layer, which assists in decreasing the wear rate and extending the service life [26-28]. This result is consistent with the wear rate and stability of the coefficient of friction mentioned above.

\subsection{Thermogravimetric analysis}

A synchronous heat analyzer was used to characterize the weight loss of the specimens before and after testing. Figure 9 shows the thermogravimetric analysis (TGA) curve of the friction-composite specimens before and after the friction test. The decomposition of all the specimens can be divided into three stages.

Given the basic properties and content of each reagent used in our experiments, the decomposed substances in the primary stage should be small organic molecules in the resins and adsorbed water. The second stage is due to the decomposition of phenolic resin and aramid pulp, together with some impurities in barite, and the last stage is the oxidation of graphite. The weight of all the specimens before the tests was greater than after the test. The specimens were most vulnerable to damage due to high temperature and pressure in the friction testing process. Considering the change in the $600-750{ }^{\circ} \mathrm{C}$ curve, it can be inferred that the

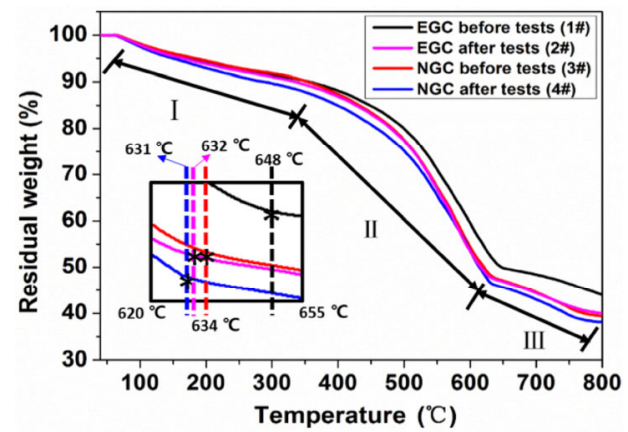

Fig. 9 TGA curves of friction composites before and after testing.

decomposition of this stage involved graphite, due to a mass loss of $\sim 5 \%$.

The residual weight of EGC was lower than that of NGC. At the last stage, the decomposition temperatures of $1 \#, 2 \#, 3 \#$, and $4 \#$ were $648,632,634$, and $631^{\circ} \mathrm{C}$, respectively. EGC had a higher decomposition temperature than NGC both before and after the test, indicating that the addition of EG created a synergistic effect thereby making the composite effective, improving the tribological properties and increasing the service life of the composites. This is in accordance with the results of the above wear morphology and wear rate results for the two specimens.

From the above results, we can conclude the mechanism of tribological behavior. As previously stated, EG has larger interlayer spacing and a more porous structure than NG. During the preparation of EGC, some phenolic resin particles and aramid pulp may enter into certain EG layers; the phenolic resin will flow along EG and gradually coat the other materials in the processes of hot pressing and curing, forming a relatively stable network structure compared to that of NGC. In the test process, the stripped NG flakes and gray iron interact on the contact surface, promoting the oxidation and cracking of the graphite layer along the iron interface in general [29, 30]. The iron oxides enter the graphite interlayer and participate in the formation of the friction layer. However, EG used here has relatively large interlamellar spacing. The iron oxide nanoparticles enter the graphite layer directly. They form a stable, thicker friction layer earlier than that formed in NGC in the friction process occurring between the composite and disc, further reducing the wear rate and increasing the stability of the coefficient of friction. This mechanistic analysis is consistent with the friction and wear results described earlier. 


\section{Conclusions}

Comparing the friction and wear properties of NGC and EGC, the following conclusions can be drawn.

(1) EGC proved excellent in the composite NGC in terms of lubrication properties and wear resistant performance. EGC exhibited better lubrication performance in the fading and recovery processes, with a lower overall coefficient of friction. The coefficient of friction could be kept in the range of $0.3-0.5$ to ensure the braking effect. The wear rate of EGC decreased by $22.43 \%$ compared to that of NGC.

(2) The EGC's coefficient of friction is more stable than that of NGC during the fading process. This result may be attributed to the fact that EG is not easily dislodged in the process of raising the temperature, thus ensuring the stability of the friction performance.

(3) The fading rates of NGC and EGC are the same $(100 \%)$. Nevertheless, NGC proved superior to EGC in its recovery performance. The recovery maintenance rate of NGC was $4.66 \%$ higher than that of EGC, because the chemical bonds were destroyed by the graphite intercalation in EG.

The trends and properties of EG (capability to improve lubricity, recovery performance, and wearreducing tendency) indicate that it can be considered an effective component to use in NAO friction materials.

\section{Acknowledgements}

This work was financially supported by the National Key Research Program of China (2016YFA0201001), Major scientific and technological innovation in Hubei (2017AAA112 and 2018AAA015), the Open research project of the Ministry of Education's Engineering Research Center of Nano-Geo Materials (NGM2017KF011), and the laboratory open foundation of the 2016-2017 academic year (SKJ2018052).

Open Access: This article is licensed under a Creative Commons Attribution 4.0 International License, which permits use, sharing, adaptation, distribution and reproduction in any medium or format, as long as you give appropriate credit to the original author(s) and the source, provide a link to the Creative Commons licence, and indicate if changes were made.

The images or other third party material in this article are included in the article's Creative Commons licence, unless indicated otherwise in a credit line to the material. If material is not included in the article's Creative Commons licence and your intended use is not permitted by statutory regulation or exceeds the permitted use, you will need to obtain permission directly from the copyright holder.

To view a copy of this licence, visit http://creativecommons.org/licenses/by/4.0/.

\section{References}

[1] Martinez A M, Echeberria J. Towards a better understanding of the reaction between metal powders and the solid lubricant $\mathrm{Sb}_{2} \mathrm{~S}_{3}$ in a low-metallic brake pad at high temperature. Wear 348-349: 27-42 (2016)

[2] Faig J J, Zhang Y Y, Man K N, Luo S J, Shough A M, Schilowitz A, Dierolf M, Uhrich K E. Thermocleavable friction modifiers for controlled release in lubricants. Tribol Int 120: 58-69 (2018)

[3] Gbadeyan O J, Kanny K. Tribological behaviors of polymerbased hybrid nanocomposite brake pad. J Tribol 140: 032003 (2018)

[4] Oshita K, Komiyama S, Sasaki S. Preparation of a micaorganic hybrid solid lubricant and characterization of its lubrication mechanisms. Tribol Int 123: 349-358 (2018)

[5] Österle W, Dmitriev A. The role of solid lubricants for brake friction materials. Lubricants 4: 5 (2016)

[6] Prabhu T R. Effects of solid lubricants, load, and sliding speed on the tribological behavior of silica reinforced composites using design of experiments. Mater Des 77: 149-160 (2015)

[7] Aranganathan N, Bijwe J. Comparative performance evaluation of NAO friction materials containing natural graphite and thermo-graphite. Wear 358-359: 17-22 (2016)

[8] Bijwe J, Kumar K, Panda J N, Parida T, Trivedi P. Design and development of high performance tribo-composites based on synergism in two solid lubricants. Compos Part B: Eng 94: 399-410 (2016)

[9] Kolluri D K, Boidin X, Desplanques Y, Degallaix G, Ghosh A K, Kumar M, Bijwe J. Effect of natural graphite particle size in friction materials on thermal localisation phenomenon during stop-braking. Wear 268: 1472-1482 (2010)

[10] Baptista R, Mendão A, Rodrigues F, Figueiredo-Pina C G, Guedes M, Marat-Mendes R. Effect of high graphite filler contents on the mechanical and tribological failure behavior of epoxy matrix composites. Theor Appl Fract Mech 85: 113-124 (2016) 
[11] Dong D, Jiang B L, Li H T, Du Y Z, Yang C. Effect of graphite target power density on tribological properties of graphite-like carbon films. Appl Surf Sci 439: 900-909 (2018)

[12] Panda J N, Bijwe J, Pandey R K. Role of treatment to graphite particles to increase the thermal conductivity in controlling tribo-performance of polymer composites. Wear 360-361: 87-96 (2016)

[13] Aranganathan N, Bijwe J. Special grade of graphite in NAO friction materials for possible replacement of copper. Wear 330-331: 515-523 (2015)

[14] Aderikha V N, Krasnov A P, Naumkin A V, Shapovalov V A. Effects of ultrasound treatment of expanded graphite (EG) on the sliding friction, wear resistance, and related properties of PTFE-based composites containing EG. Wear 386-387: 63-71 (2017)

[15] Huang Z W, Luo Z G, Gao X N, Fang X M, Fang Y T, Zhang $Z$ G. Investigations on the thermal stability, long-term reliability of $\mathrm{LiNO}_{3} / \mathrm{KCl}$ - expanded graphite composite as industrial waste heat storage material and its corrosion properties with metals. Appl Energy 188: 521-528 (2017)

[16] Xu C B, Wang H L, Yang W J, Ma L K, Lin A J. Expanded graphite modified by $\mathrm{CTAB}-\mathrm{KBr} / \mathrm{H}_{3} \mathrm{PO}_{4}$ for highly efficient adsorption of dyes. J Polym Environ 26: 1206-1217 (2018)

[17] Dinker A, Agarwal M, Agarwal G D. Preparation, characterization, and performance study of beeswax/expanded graphite composite as thermal storage material. Exp Heat Transfer 30: 139-150 (2017)

[18] Struchkova T S, Okhlopkova A A, Sleptsova S A. Triboengineering properties of polytetrafluoroethylene modified by thermally expanded graphite. J Frict Wear 29: 381-385 (2008)

[19] Wang L L, Zhang L Q, Tian M. Effect of expanded graphite (EG) dispersion on the mechanical and tribological properties of nitrile rubber/EG composites. Wear 276-277: 85-93 (2012)

[20] Jia Z N, Hao C Z, Yan Y H, Yang Y L. Effects of nanoscale expanded graphite on the wear and frictional behaviors of polyimide-based composites. Wear 338-339: 282-287 (2015)

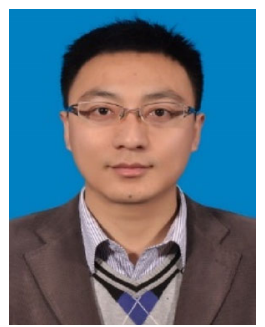

Hongyun JIN. He obtained B.E. degree in 2000 and Ph.D. degree in 2009 from the Department of Materials Science and Engineering, China University of Geosciences (Wuhan). Afterward, he worked as
[21] Ji Z J, Jin H Y, Luo W Y, Cheng F R, Chen Y, Ren Y Z, $\mathrm{Wu}$ Y Q, Hou S E. The effect of crystallinity of potassium titanate whisker o $\mathrm{n}$ the tribological behavior of NAO friction materials. Tribol Int 107: 213-220 (2017)

[22] Wu Y Q, Zeng M, Xu Q Y, Hou S E, Jin H Y, Fan L R. Effects of glass-to-rubber transition of thermosetting resin matrix on the friction and wear properties of friction materials. Tribol Int 54: 51-57 (2012)

[23] Ji Z J, Luo W Y, Zhou K K, Hou S E, Zhang Q F, Li J Y, Jin $H$ Y. Effects of the shapes and dimensions of mullite whisker on the friction and wear behaviors of resin-based friction materials. Wear 406-407: 118-125 (2018)

[24] Yan Z X, Xia H M, Lan Y H, Xiao J H. Variation of the friction coefficient for a cylinder rolling down an inclined board. Phys Edu 53: 015011 (2018)

[25] Cygan S, Jaworska L, Putyra P, Ratuszek W, Cyboron J, Klimczyk P. Thermal stability and coefficient of friction of the diamond composites with the titanium compound bonding phase. J Mater Eng Perform 26: 2593-2598 (2017)

[26] Verma P C, Ciudin R, Bonfanti A, Aswath P, Straffelini G, Gialanella $\mathrm{S}$. Role of the friction layer in the high-temperature pin-on-disc study of a brake material. Wear 346-347: 56-65 (2016)

[27] Xiao X M, Yin Y, Bao J S, Lu L J, Feng X J. Review on the friction and wear of brake materials. Adv Mech Eng 8: 1-10 (2016)

[28] Xu S S, Zheng J Y, Hao J Y, Kong L G, Liu W M. Wear resistance of superior structural $\mathrm{WS}_{2}-\mathrm{Sb}_{2} \mathrm{O}_{3} / \mathrm{Cu}$ nanoscale multilayer film. Mater Des 93: 494-502 (2016)

[29] Hinrichs R, Vasconcellos M A Z, Österle W, Prietzel C. A TEM snapshot of magnetite formation in brakes: The role of the disc's cast iron graphite lamellae in third body formation. Wear 270: 365-370 (2011)

[30] Österle W, Orts-Gil G, Gross T, Deutsch C, Hinrichs R, Vasconcellos M A Z, Zoz H, Yigit D, Sun X. Impact of high energy ball milling on the nanostructure of magnetitegraphite and magnetite-graphite-molybdenum disulphide blends. Mater Charact 86: 28-38 (2013)

a visiting scholar in University of Washington. He works on nano energy materials, friction materials, and thermal barrier coatings. He has published over 50 papers and got the prizes in Hubei Province Science and Technology Award in 2011 and 2015. 


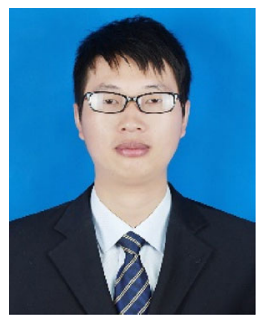

Keke ZHOU. He received his B.E. degree in 2016 from Anhui Science and Technology University. Now he is a graduate student at China

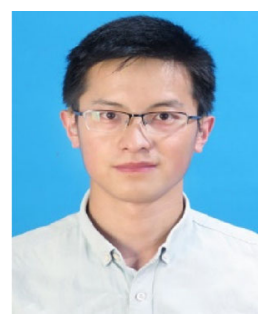

Zhengjia JI. He received the Ph.D. degree in materials science and engineering from China University of Geosciences (Wuhan) in 2017. He is currently a postdoctoral fellow

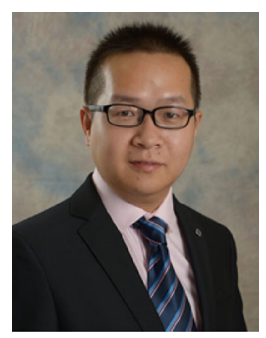

Xiaocong TIAN. He received his Ph.D. degree in 2016 from Wuhan University of Technology under the supervision of Prof. Liqiang MAI. Afterward, he worked as a postdoctoral research fellow working

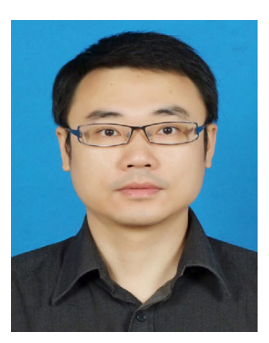

Ying CHEN. He received his B.S. and Ph.D. degrees from China University of Geosciences (Wuhan). Then, he worked as a visiting scholar in the Department of Mechanical and Materials Engineering at the Western University (2008-2010).

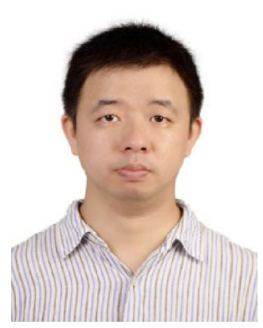

Luhua LU. He obtained B.E. degree in 2004 from the School of Materials Science and Engineering, Wuhan University of Technology, and Ph.D. degree in 2010 from Suzhou Institute of Nano-Tech and Nano-Bionics,
University of Geosciences (Wuhan). His current research mainly focuses on controllable synthesis and application of various components for friction materials.

at State Key Laboratory of Tribology of Tsinghua University. He has published more than 10 papers in international journals. His major research areas include friction materials, self-lubrication materials, and 2D materials.

with Prof. Kun ZHOU at the Singapore Centre for 3D Printing, Nanyang Technological University, Singapore. $\mathrm{He}$ is currently an associate professor at China University of Geosciences (Wuhan). His research interests include 3D printing and novel nanomaterials.

Currently, He is an associate professor in the School of Material Science and Engineering at China University of Geosciences (Wuhan) from 2011. His research interests focus on controllable synthesis of novel sulfide nanostructures targeted for electrochemical energy storage, such as anode materials for lithium-ion batteries and supercapacitors.

Chinese Academy of Sciences, China. He works on design and synthesis of functional nanomaterials, electrochemical and photochemical energy storage, and conversion. He has published over 60 papers since 2010 . 


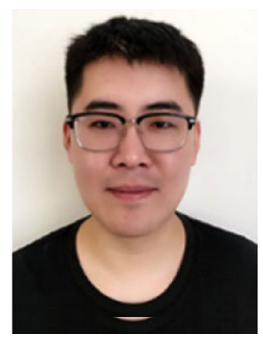

Yazhou REN. He received his B.E. degree in engineering from China University of Geosciences (Wuhan) in 2016. He is now a graduate

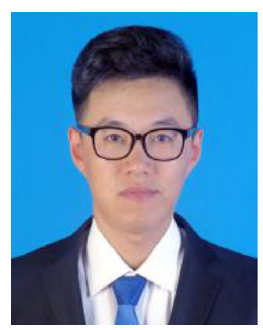

Chunhui XU. He obtained B.S. degree in 2013 from the China University of Petroleum (East China). He obtained Ph.D. degree in

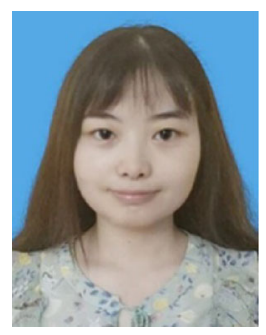

Shanshan DUAN. She obtained her B.E. degree in engineering in 2015 from China University of Geosciences (Wuhan). Now she is

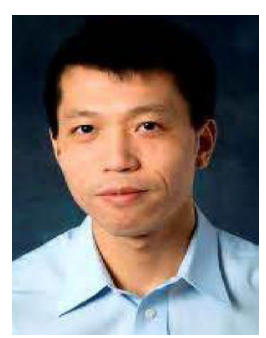

Jiangyu LI. He obtained B.E. degree in 1994 from the Department of Materials Science and Engineering, Tsinghua University, and Ph.D. in 1998 from the Department of Mechanical Engineering, University of Colorado Boulder, USA. His works on mechanics of materials, scanning probe microscopies, and phase field

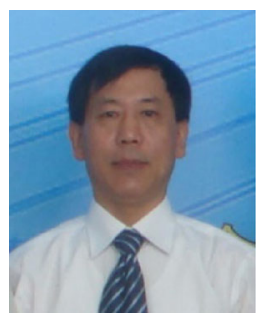

Shu-en HOU. He obtained Ph.D. degree in 2001 from the Department of Materials Science and Engineering, China University of Geosciences (Wuhan). Afterward, he has worked student of materials sciences and engineering in China University of Geosciences (Wuhan). His research mainly focuses on friction materials.

2018 from the China University of Geosciences (Wuhan). Afterward, he is an engineer and works on nano materials in friction and thermal barrier coatings.

a Ph.D. student at China University of Geosciences (Wuhan). Her current research mainly focuses on nanomaterials and solid state batteries.

simulations. He has published over 200 papers. He has been recognized by Sia Nemat-Nasser Medal from ASME and Microscopy Today Innovation Award from Microscopy Today, and he serves as an associate editor for Journal of Applied Physics and Science Bulletin. He also sits on editorial boards of NPJ Computational Materials and Journal of Materiomics.

as a visiting scholar at University of Texas at Austin, USA. He works on nanomaterials in thermal barrier coatings, friction materials and so on. He has published over 100 papers. He has got the prize in Hubei Province Science and Technology Award. 